\title{
NATURAL COLORATION OF WOOD MATERIAL BY RED BEETROOT (Beta vulgaris) AND DETERMINATION COLOR STABILITY UNDER UV EXPOSURE
}

\author{
Mehmet Yeniocak $^{1, \wedge}$, Osman Goktas ${ }^{1}$, Mehmet Colak ${ }^{1}$, Ertan Ozen $^{1}$, Mehmet Ugurlu ${ }^{2}$
}

\begin{abstract}
This study is aimed to develop an eco-friendly wood stained extracted from beetroot (Beta vulgaris) and determine the color stability of this stain to UV light irradiation. Natural dyestuff were extracted from beetroot by ultrasonic-assisted method and prepared from aqueous solution with ferrous sulphate, aluminum sulphate, copper sulphate and vinegar mordant mixes. Scots pine (Pinus sylvestris), oriental beech (Fagus orientalis), oak (Quercus petraea) and walnut (Juglans regia) wood specimens were used for the study. After treatment with stain, wood specimens were exposed to UV irradiation for periods of 50,100 and 150 hours. Results showed that the color change values for all wood specimens colored with beetroot extract had better performance compared to synthetic dye. Beetroot extracts may be used as an upper surface dyestuff for indoor application and toys. Therefore, alternative to synthetic dyes more economical and eco-friendly, wood paints may be developed.
\end{abstract}

Keywords: Beetroot, color changes, natural coloration, UV weathering.

\section{INTRODUCTION}

Wood is commonly used for different purposes ranging from high-performance constructions to filigree art work. In most applications, the appearance of the surface is crucial for costumer decisions (Bechtold and Mussak 2009). Generally wood materials need to preservation and coloring by chemicals in terms of environmental health in recent years. Recently international awareness of environment, ecology and pollution control created an upsurge on the interest of people to use more environmentally products. Natural dyes derived from flora and fauna are believed to be safe because of their non-toxic, non-carcinogenic and biodegradable nature (Mirjalili et al. 2011). For this reason, the importance of the protection of wood material by natural sources is gaining importance day by day.

Wood-based products and decoration elements are potential sources for a number of volatile organic compounds (VOCs) that may be released indoors (Goktas et al. 2009c). Many chemical components are used in wood finishes and coatings industry. Salthammer et al. 1998, identified about 150 different VOCs. The formation of organic indoor pollutants by chemical reaction in indoor air has been extensively studied (Weschler 1997, Salthammer 2002). Moreover, many building products contain reactive compounds, which decompose under normal living conditions and can be released as secondary emission products (Salthammer 1999). These pollutants are emitted from different sources such as floor coverings, wood-based panel, furniture, solid woods, wood stains and paints (Cheng and Brown 2003). Billions of people in the world suffer from diseases resulting from low air quality, and trillions of dollars are spent to compensate for such problems (Mo et al. 2009). For many years, it has been known that many synthetic dyes are dangerous to human health, and the industry has been seeking environmentally friendly products (Peker et al. 2012).

\footnotetext{
${ }^{1}$ Department of Woodworking Industrial Engineering, Faculty of Technology, Mugla Sitki Kocman University, Mugla, 48000, Turkey

2 Department of Chemistry, Faculty of Science, Mugla Sitki Kocman University, Mugla, 48000, Turkey.

- Corresponding author: myeniocak@mu.edu.tr

Received: 02.09.2014 Accepted: 30.04.2015.
} 
Goktas et al. investigated the development of environmentally friendly wood stains derived from laurel (Laurus nobilis) (2008a), oleander (Nerium Oleander) (2009a), and madder root (Rubia tinctorium) (2009b) and determined the color stability of the stains when exposed to ultra-violet (UV) light irradiation. Their results showed that the wood stains derived from laurel, oleander, and madder root extract provided some color stability after UV irradiation. Goktas et al. 2008b, investigated the antifungal properties and color stability under UV exposure of wood treated with aqueous solutions of Juglans regia extract. Results showed that the lightness values of the wood specimens did change slightly. Peker et al. 2012, investigated the color stability of acorn (Quercus ithaburensis) and reported that acorn has an aesthetic appearance as a coloring and preservative upper surface material.

Nowadays many natural roots were mentioned as a natural dye source in various scientific researches. Junqueira-Goncalves et al. 2011, investigated the beetroot extract as a colorant for cream cheese, they reported that beetroot extracts might be a potential alternative dye for food. Sivakumar et al. 2009, has been studied on the use of power ultrasound to improve the extraction of beetroot dye and application to the substrates such as leather and they reported that the beetroot is suitable for dying leather.

Betanin, obtained from the roots, is used industrially as red food colorants, e.g. to improve the color and flavor of tomato paste, sauces, desserts, jams and jellies, ice cream, sweets, and breakfast cereals (Grubben and Denton 2004). Beetroot dye may also be used in ink. Within older bulbs of beetroot, the color is a deep crimson, and the flesh is much softer.

In Turkey, there is a large production and consumption, while in the Aegean and Marmara regions in the Mediterranean region beetroot is produced in limited quantities. There are currently 7286 tons harvests every year in Turkey. Only pickling beetroot are used as industrial sense. Red beets are a potential source to use as a wood colorant whereof it contains substances which were very rich and beautiful colors. These substances have been used for textiles and food but have never been used as natural colorants in wood industry.

In this study we have focused on the coloring wood material by red beetroot extract and mordant mixes to determine their properties of color change after UV weathering and durability after leaching. Another aim is to utilize the potential of natural sources as a substitute colorant for synthetic dyes.

\section{MATERIALS AND METHODS}

\section{Wood materials}

As wood material, Scots pine (Pinus sylvestris), oriental beech (Fagus orientalis), oak (Quercus petraea) and walnut (Juglans regia) woods commonly used in furniture and decoration industries in Turkey were chosen. The samples were prepared from first-class wooden materials, which are smooth fiber, knotless, crack-free, without color and density difference, with annual rings perpendicular to the surfaces, and from parts of sapwood, in accordance with TS 2470 standards (TS 2470, 2005). The samples prepared for light fastness tests with dimensions of $150 \times 75 \times 0,5 \mathrm{~mm}$ and for leaching tests with $19 \times 19 \times 19 \mathrm{~mm}$ and were kept under suitable temperature $\left(20 \pm 2^{\circ} \mathrm{C}\right)$ and suitable moisture (moisture of $\pm 12 \%$ and relative humidity of $\pm 65 \%$ ) conditions until they became air-dried, in order to achieve the moisture value in furniture used under interior area conditions in accordance with TS 2471, 2005 standard.

\section{Plant material and Mordant agents}

In this study, the red beetroot was gathered from the Muğla area (Turkey). Mordant agents ferrous sulphate $\left(\mathrm{Fe}_{2}\left(\mathrm{SO}_{4}\right)_{3} 7 \mathrm{H}_{2} \mathrm{O}\right)$, aluminum sulphate $\left(\mathrm{Al}_{2}\left(\mathrm{SO}_{4}\right)_{3} 18 \mathrm{H}_{2} \mathrm{O}\right)$ and copper sulphate $\left(\mathrm{CuSO}_{2} 5 \mathrm{H}_{2} \mathrm{O}\right)$ were provided from Kimetsan Co. and vinegar was purchased from Fersan Co. The synthetic dye used for comparison; woodtex - wood colorant was supplied from Kayalar kimya Co. 


\section{Preparation of dyestuff}

A weighed amount of dry plant material was extracted with distilled water in a ultrasonic bath (Elmasonic X-tra $150 \mathrm{H}$ ). In the standard procedure the mass ratio of plant material to the volume of liquid was 1:20; extraction was performed for approximately. $180 \mathrm{~min}$ at $45^{\circ} \mathrm{C}$ and $180 \mathrm{~W}$ sonic power in a stainless ultrasonic bath. Due to the rather high liquor ratio some manual stirring was sufficient to distribute the plant material in the liquid during the extraction period. Volume loss due to evaporation was compensated by the addition of water at the end of the extraction period to obtain the initial volume. Ultrasound-assisted extraction is an inexpensive, simple and efficient alternative to conventional extraction techniques. The main benefits of using ultrasound in solid-liquid extraction include the increase of extraction yield and faster kinetics. Ultrasound can also reduce the operating temperature allowing the extraction of thermolabile compounds. Compared with other novel extraction techniques such as microwave-assisted extraction, the ultrasound apparatus is cheaper and its operation is easier (Wang and Weller 2006).

Aqueous solutions were mordanted by adding ferrous sulphate $\left(\mathrm{Fe}_{2}\left(\mathrm{SO}_{4}\right)_{3} 7 \mathrm{H}_{2} \mathrm{O}\right) 3 \%$, aluminum sulphate $\left(\mathrm{KAl}_{2}\left(\mathrm{SO}_{4}\right)_{3} 18 \mathrm{H}_{2} \mathrm{O}\right) 5 \%$, copper sulphate $\left(\mathrm{CuSO}_{2} 5 \mathrm{H}_{2} \mathrm{O}\right) 5 \%$, and grape vinegar $10 \%$ in order to stabilize the color of extracted dyes, to ensure it to hang on to the applied material (to increase retention amount), and to create color options.

\section{Dyeing test samples}

The air-dried wood specimens were placed into ultrasonic bath container according to their intended treatments. Treatment procedures are given in Table 1. In the treatment two different methods (immersion and ultrasonic-assisted immersion) of dyeing were used. Any extra solution left on the specimens was removed with a clean cloth. Specimens were then left to dry at $20 \pm 3{ }^{\circ} \mathrm{C}$ in a vertical position.

Table 1. Treatment Procedures.

\begin{tabular}{ccccc}
\hline Dye & Treatment Method & Sonic Power $(\mathrm{W})$ & Temperature $\left({ }^{\circ} \mathrm{C}\right)$ & Time $(\mathrm{min})$ \\
\hline \multirow{2}{*}{ Natural } & $\begin{array}{c}\text { Control (immersion) } \\
\text { Ultrasonic-assisted } \\
\text { immersion }\end{array}$ & --- & 45 & 60 \\
\hline \multirow{2}{*}{ Synthetic } & $\begin{array}{c}\text { Control (immersion) } \\
\text { Ultrasonic-assisted } \\
\text { immersion }\end{array}$ & --- & 45 & 60 \\
\hline
\end{tabular}

\section{Accelerated weathering test}

Operation of accelerated weathering device is composed of two periods. The first is condensation stage. This stage ensures the sample pieces to expand by changing the temperature, coolness, and moisture amount of the environment at regular intervals in order to imitate the external environment conditions and by spraying hot steam thereon. In the second stage, the test pieces were subjected to UV beams by using UV lamps. Weathering process was performed by operating the device for $4 \mathrm{~h}$ in the condensation stage, and for $8 \mathrm{~h}$ in UV period. The average irradiance was about $330 \mathrm{~nm}$ at 50 percent relative humidity and $20^{\circ} \mathrm{C}$. Specimens were directly exposed to UV light at a distance of $20 \mathrm{~cm}$ and an angle of 90E (Kamdem and Grelier 2002). Eight replicate samples treated with each stain solution and untreated controls were run for the randomly selected irradiation times of 0 (no irradiation), 50 hours, 100 hours, and 150 hours The color of the samples was measured after each irradiation period. 


\section{Color measurements}

In order to determine the color change values in the accelerated weathering tests, the colors of the coated parts were identified prior to weathering by using Konica Minolta CR-10, a portable color reader device. Color measurements were performed on each sample due to the non-homogenous color structure of the wooden material in four measures. The identified color values were classified according to the coordinates Commission International de I'Eclaireage-CIELAB 1976 set in ISO 2470 standards (Figure 1). The obtained colors were indicated with numerical values of $\mathrm{L}$, a, and b. Here, $\mathrm{L}$ indicates lightness from $0 \%$ (black) and $100 \%$ (white), a from green (-a) to red $(+a)$, and $b$ from blue (-b) to yellow $(+b)$. Coated sample pieces were subjected to color measure prior being exposed to accelerated weathering environment and stated as "color values prior to accelerated weathering". Afterwards, the coated samples were placed on the weathering device, exposed to UV and condensation environment for $50 \mathrm{~h}$, and color measurement was carried out again from the same cross-corners. This process was repeated at the 100th and 150 th $\mathrm{h}$.

\section{Determination of color change values}

Color changes due to accelerated weathering were calculated with the following formulas in accordance with ISO 2470 standards.

$$
\begin{aligned}
& \Delta L^{*}=L_{f}^{*}-L_{i}^{*} \\
& \Delta a^{*}=a_{f}^{*}-a_{i}^{*} \\
& \Delta b^{*}=b_{f}^{*}-b_{i}^{*} \\
& \Delta E^{*}=\sqrt{\Delta L^{* 2}+\Delta a^{* 2}+\Delta b^{* 2}}
\end{aligned}
$$

Here; $\Delta L^{*}, \Delta a^{*}$ and $\Delta b^{*}$ are the changes occurring between the initial state (i) and final state (f) of the colors. $\Delta E^{*}$, indicates total changes of the colors occurring in $\mathrm{L}, \mathrm{a}$, and $\mathrm{b}$. Here, the highest value shows the highest color change.

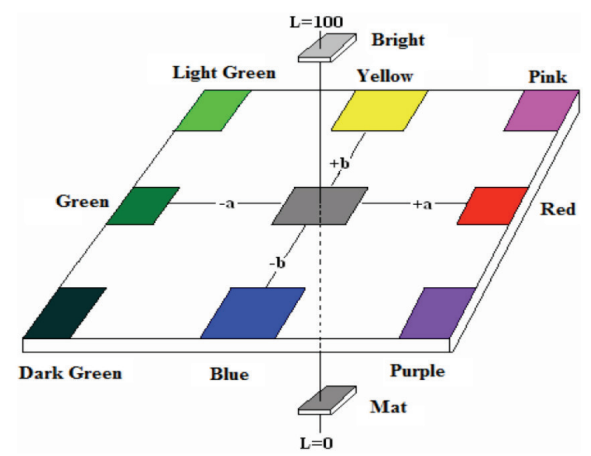

Figure 1. CIELAB-76 color system (Goktas et al. 2008). 


\section{RESULTS AND DISCUSSION}

Color changes values occurring on Scots pine, oriental beech, walnut and oak wood test samples stained with beetroot extracts and mordant mixes extracts and exposed to UV application for 50, 100, and $150 \mathrm{~h}$ are numerically represented in Tables 1 and 2 . A schematic representation is given for beetroot and mordant mixes extracts in Figure 2.

Positive values of $\Delta L^{*}$ show whitening, and negative values of $\Delta L^{*}$ indicate the color turning grey. Positive values of $\Delta a^{*}$ indicate reddening of the colors, and negative values of $\Delta a^{*}$ show a shift towards green. Positive values of $\Delta b^{*}$ represent yellowing in color, and negative values of $\Delta b^{*}$ represent the color turning blue.

In the process of wood photodegradation, the first phenomenon observed is the color change, followed by the loss of fibers and surfaces erosion. The erosion process is slow and depends on several factors such as anatomy of wood, density, proportion of earlywood and latewood, grain angle and angle of exposure (Williams 2005, Garcia et al. 2014). According to the results, all wood specimens exposed to UV radiation of $350 \mathrm{~nm}$ for all the exposure periods generally showed negative values of $\Delta L^{*}$. This was attributed to chemical changes which occurred, especially in lignin, due to photo-degradation resulting from UV exposure and, consequently, to a darkening of color on the wood (Peker et al. 2012, Ozen et al. 2014). The high negative values of $\Delta L^{*}$ indicate the sensitivity of that wood type against UV radiation and the surface quality thereof (Feist and Hon 1984).

In general, it is realized that color changes occurs quickly in $50 \mathrm{~h}$ and $100 \mathrm{~h}$ periods; during the following period less changes occurred. The first part of the color change process is because of the formation of chromophoric groups as carbonyl and carboxyl groups resulting mainly from degradation of $\alpha$-carbonyl, biphenyl and ring-conjugated double bond structures in lignin and moving of the extractives towards to wood surface from inside of wood (Lin and Kringstad 1970, Hon and Feist 1992). Relatively more quick change is reported even if the wood material is exposed to UV light in external environment for short period or under accelerated weathering (Feist and Hon 1984, Peker et al. 2012).

The best color stability $\left(\Delta E^{*} 28,31\right)$ was attained for scots pine wood with beetroot + vinegar mixes and dyed by classical method after $150 \mathrm{~h}$ of exposure.

The biggest color change was seen on scots pine species dyed with beetroot + ferrous sulphate mixes. Generally color changes on scots pine species showed similar results with all dyestuff types (expect beetroot + ferrous sulphate). When we look at the color changes on beech wood species the lowest change was $\left(\Delta E^{*} 18,72\right)$ acquired for control (without mordant) and the biggest change $\left(\Delta E^{*} 35,40\right)$ for beetroot + ferrous sulphate mixes.

The lowest color change value $\left(\Delta E^{*} 12,07\right)$ is obtained from the application of control (without mordant) on walnut wood species, and the highest color change value $\left(\Delta E^{*} 27,80\right)$ from the application of beetroot + ferrous sulphate mixes.

According to the color changes of the oak wood species, the lowest change was $\left(\Delta E^{*} 14,11\right)$ acquired for control (without mordant) and the highest color change was $\left(\Delta E^{*} 37,44\right)$ performed from the application of beetroot + ferrous sulphate mixes. 
Generally all wood species have darker color with beetroot + ferrous sulphate mixes and wood species colored by beetroot + ferrous sulphate mixes had large color change values compared to other components. These changes may be explained with interaction of ferrous sulphate ions and wood components. Metal mordant have been pointed out as the reason for color stability. Because metal ions, promotes free radical formation (Feist and Hon 1984, Peker et al. 2012) of wood components even when they are exposed to light. The stabilization of lignin by ferrous was reported to occur through the formation of complex (Kamdem and Grelier 2002).

The reason for the differences between wood types may be due to the differences of chemical composition of the wood types, and interaction of beetroot and mordant mixes extract compounds with wood component, resulting in the different photo-degradation effects of UV irradiation. Feist and Hon (1984) reported that higher color changes were found in samples having higher lignin content. Lignin is the compound absorbing UV of 80 to $95 \%$ among the three main components of wood (Peker et al. 2012). Besides, generally soft woods have $2-10 \%$ more lignin than hard woods (Tereza et al. 2004, Goktas et al. 2009b). Lignin has aromatic, phenolic and carboxylic groups that absorb rays of different energy levels. Although cellulose is not sensitive to UV light of wavelengths longer than $340 \mathrm{~nm}$ (Feist and Hon 1984). Nevertheless, the roughness of color stabilized wood is a complex phenomenon because wood is an anisotropic and heterogeneous material. Several factors, such as anatomical differences, growing characteristics, machining properties, pre-treatments (e.g. steaming, drying, etc.), can affect the color stability (Temiz et al. 2005, Goktas et al. 2009b). Also, the treatments parameters as treatment time, percentage of dyer materials, application temperature and percentage of mordant may affect the color stability. 
Table 2. Color Change values UV Application for $50 \mathrm{~h}, 100 \mathrm{~h}$ and $150 \mathrm{~h}$ for dyed test sample.

\begin{tabular}{|c|c|c|c|c|c|c|c|c|c|c|c|c|c|c|c|c|c|c|}
\hline \multirow{2}{*}{ Wood type } & \multirow{2}{*}{$\begin{array}{l}\text { Dyeing } \\
\text { Method }\end{array}$} & \multirow{2}{*}{ ye extract } & \multicolumn{4}{|c|}{ After dyeing } & \multicolumn{4}{|c|}{ After 50 h } & \multicolumn{4}{|c|}{ After $100 \mathrm{~h}$} & \multicolumn{4}{|c|}{ After $150 \mathrm{~h}$} \\
\hline & & & $\Delta L^{*}$ & $\Delta a^{*}$ & $\Delta b^{*}$ & $\Delta E^{*}$ & $\Delta L^{*}$ & $\Delta a^{*}$ & $\Delta b^{*}$ & $\Delta E^{*}$ & $\Delta L^{*}$ & $\Delta a^{*}$ & $\Delta b^{*}$ & $\Delta E^{*}$ & $\Delta L^{*}$ & $\Delta a^{*}$ & $\Delta b^{*}$ & $\Delta E^{*}$ \\
\hline \multirow{12}{*}{ 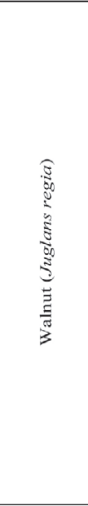 } & \multirow{6}{*}{ 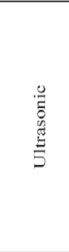 } & $\begin{array}{c}\text { Control } \\
\text { (Without Mordant) }\end{array}$ & $-2,29$ & 1,00 & 1,99 & 3,19 & $-4,67$ & 3,61 & 8,57 & 10,40 & $-6,06$ & $-6,06$ & 8,96 & 11,87 & $-7,38$ & 4,82 & 8,25 & 12,07 \\
\hline & & Beet + Ferrous & $-25,46$ & $-6,29$ & $-15,94$ & 30,68 & $-21,72$ & $-6,95$ & $-9,63$ & 24,75 & $-21,24$ & $-6,88$ & $-9,18$ & 24,14 & $-21,81$ & $-6,61$ & $-7,96$ & 24,14 \\
\hline & & Beet + Alum & $-2,33$ & 0,04 & $-0,42$ & 2,37 & $-4,98$ & 2,76 & 5,39 & 7,83 & $-8,38$ & 4,44 & 5,87 & 11,15 & $-9,47$ & 4,59 & 6,18 & 12,20 \\
\hline & & Beet + Copper & $-5,95$ & $-0,16$ & $-0,15$ & 5,95 & $-8,82$ & 1,87 & 5,66 & 10,64 & $-12,72$ & 2,36 & 5,81 & 14,18 & $-13,39$ & 2,50 & 5,01 & 14,51 \\
\hline & & Beet + Vinegar & $-3,57$ & 1,44 & 1,83 & 4,26 & $-5,29$ & 4,50 & 8,99 & 11,36 & $-6,91$ & 5,34 & 9,74 & 13,08 & $-7,87$ & 5,64 & 9,77 & 13,75 \\
\hline & & Synthetic Dye & $-11,52$ & 5,00 & 3,57 & 13,05 & $-11,58$ & 6,63 & 5,97 & 14,62 & $-12,85$ & 7,63 & 5,87 & 16,05 & $-11,90$ & 8,71 & 6,94 & 16,29 \\
\hline & \multirow{6}{*}{ 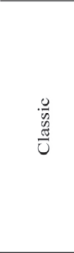 } & $\begin{array}{c}\text { Control } \\
\text { (Without Mordant) }\end{array}$ & $-2,94$ & 0,87 & 2,69 & 4,08 & $-5,36$ & 3,69 & 8,31 & 10,55 & $-7,27$ & 5,10 & 8,04 & 11,98 & $-8,91$ & 6,01 & 7,51 & 13,11 \\
\hline & & Beet + Ferrous & $-25,33$ & $-7,23$ & $-16,65$ & 31,16 & $-25,09$ & $-6,76$ & $-12,17$ & 28,69 & $-24,75$ & $-6,67$ & $-10,45$ & 27,68 & $-25,34$ & $-6,29$ & $-9,56$ & 27,80 \\
\hline & & Beet + Alum & $-3,46$ & $-3,46$ & 1,06 & $-0,18$ & $-7,05$ & 3,96 & 6,47 & 10,35 & $-10,45$ & 5,25 & 7,14 & 13,70 & $-12,06$ & 6,19 & 6,75 & 15,14 \\
\hline & & Beet + Copper & $-4,42$ & 0,16 & 0,16 & 4,42 & $-8,73$ & 1,62 & 6,10 & 10,77 & $-11,04$ & 2,30 & 6,35 & 12,93 & $-12,47$ & 2,80 & 5,65 & 13,97 \\
\hline & & Beet + Vinegar & $-1,94$ & 0,85 & 0,81 & 2,26 & $-3,24$ & 3,08 & 9,40 & 10,40 & $-5,31$ & 5,40 & 11,13 & 13,46 & $-7,55$ & 6,01 & 9,83 & 13,78 \\
\hline & & Synthetic Dye & $-11,41$ & 5,15 & 6,08 & 13,91 & $-11,20$ & 6,41 & 9,30 & 15,90 & $-11,56$ & 6,805 & 10,58 & 17,08 & $-10,61$ & 8,23 & 11,55 & 17,71 \\
\hline \multirow{12}{*}{ 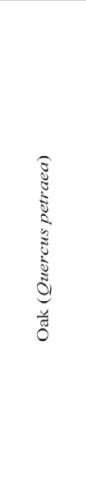 } & \multirow{6}{*}{ 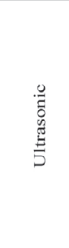 } & $\begin{array}{c}\text { Control } \\
\text { (Without Mordant) }\end{array}$ & $-2,13$ & 0,65 & 2,69 & 3,49 & $-1,81$ & 0,20 & 3,13 & 3,62 & $-4,52$ & $-4,52$ & 11,91 & 13,39 & $-6,70$ & 5,18 & 11,56 & 14,33 \\
\hline & & Beet + Ferrous & $-32,86$ & $-8,16$ & $-19,87$ & 39,26 & $-33,12$ & $-7,43$ & $-15,56$ & 37,33 & $-33,64$ & $-7,25$ & $-14,05$ & 37,17 & $-33,52$ & $-7,02$ & $-13,64$ & 36,86 \\
\hline & & Beet + Alum & $-4,56$ & 0,99 & 0,59 & 4,70 & $-9,66$ & 4,78 & 8,30 & 13,60 & $-12,18$ & 7,80 & 11,20 & 18,29 & $-15,10$ & 8,51 & 9,44 & 19,73 \\
\hline & & Beet + Copper & $-18,85$ & $-2,01$ & $-4,40$ & 19,46 & $-18,72$ & $-1,33$ & 0,08 & 18,77 & $-20,28$ & 3,08 & 0,31 & 20,51 & $-22,55$ & 0,67 & 1,58 & 22,61 \\
\hline & & Beet + Vinegar & $-2,09$ & 0,52 & 0,93 & 2,35 & $-5,51$ & 3,69 & 9,43 & 11,52 & $-6,84$ & 4,48 & 12,20 & 14,69 & $-8,86$ & 6,68 & 10,33 & 15,16 \\
\hline & & Synthetic Dye & $-10,68$ & 6,85 & 6,76 & 14,38 & $-13,37$ & 8,83 & 8,56 & 18,17 & $-14,46$ & 8,975 & 10,18 & 19,83 & $-14,69$ & 9,20 & 8,57 & 19,33 \\
\hline & \multirow{6}{*}{$\begin{array}{l}\frac{g}{D} \\
\frac{d}{d} \\
\frac{d}{u}\end{array}$} & $\begin{array}{c}\text { Control } \\
\text { (Without Mordant) }\end{array}$ & $-1,36$ & 0,11 & 3,22 & 3,50 & 1,28 & $-0,13$ & 3,35 & 3,5 & 03 & 3,87 & 11,27 & 3 & $-7,74$ & 3 & 68 & 4,11 \\
\hline & & Beet + Ferrous & $-34,05$ & $-8,26$ & $-22,46$ & 41,62 & $-33,42$ & $-8,51$ & $-21,14$ & 40,45 & $-33,48$ & $-8,15$ & $-16,00$ & 37,98 & $-33,51$ & $-7,68$ & $-14,84$ & 37,44 \\
\hline & & Beet + Alum & $-5,35$ & $-5,35$ & $-0,34$ & 0,11 & $-9,96$ & 3,31 & 7,56 & 12,93 & $-11,94$ & 5,48 & 9,28 & 16,08 & $-15,41$ & 6,68 & 8,31 & 18,74 \\
\hline & & Beet + Copper & $-17,05$ & $-0,30$ & $-4,10$ & 17,54 & $-18,79$ & $-0,14$ & 1,90 & 18,89 & $-20,37$ & 0,23 & 2,50 & 20,52 & $-23,08$ & 1,85 & 3,43 & 23,41 \\
\hline & & Beet + Vinegar & $-1,03$ & 0,52 & 3,21 & 3,41 & $-5,40$ & 4,07 & 11,10 & 12,99 & $-9,83$ & 4,73 & 10,81 & 15,36 & $-7,37$ & 6,04 & 10,66 & 14,29 \\
\hline & & Synthetic Dye & $-14,97$ & 7,53 & 6,65 & 18,02 & $-13,52$ & 8,47 & 11,33 & 19,56 & $-14,49$ & 9,145 & 11,85 & 20,83 & $-15,72$ & 9,43 & 11,44 & 21,60 \\
\hline \multirow{12}{*}{ 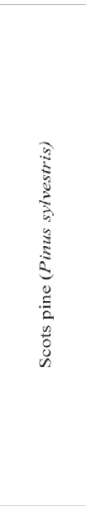 } & \multirow{6}{*}{ 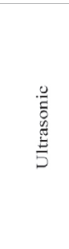 } & $\begin{array}{c}\text { Control } \\
\text { (Without Mordant) }\end{array}$ & $-6,07$ & 1,90 & 3,33 & 7,17 & $-14,67$ & 9,01 & 14,30 & 22,38 & $-20,05$ & $-20,05$ & 17,14 & 29,52 & $-22,84$ & 14,83 & 17,58 & 32,41 \\
\hline & & Beet + Ferrous & $-34,61$ & $-2,94$ & $-13,37$ & 37,22 & $-40,76$ & $-1,45$ & $-9,29$ & 41,83 & $-43,68$ & $-1,21$ & $-10,00$ & 44,82 & $-45,52$ & 0,02 & $-10,21$ & 46,65 \\
\hline & & Beet + Alum & $-6,45$ & 2,44 & 0,61 & 6,92 & $-18,86$ & 12,01 & 12,80 & 25,76 & $-24,60$ & 15,07 & 14,43 & 32,25 & $-27,67$ & 16,94 & 13,62 & 35,18 \\
\hline & & Beet + Copper & $-10,33$ & $-2,83$ & 0,01 & 10,71 & $-17,29$ & 2,65 & 11,50 & 20,93 & $-21,31$ & 4,36 & 11,84 & 24,76 & $-26,09$ & 8,95 & 13,23 & 30,59 \\
\hline & & Beet + Vinegar & $-4,70$ & 2,73 & 1,95 & 5,77 & $-14,57$ & 11,34 & 13,96 & 23,14 & $-18,33$ & 13,93 & 15,53 & 27,77 & $-22,40$ & 15,02 & 15,52 & 31,12 \\
\hline & & Synhetic Dye & $-23,26$ & 18,56 & 11,95 & 32,06 & $-27,52$ & 20,50 & 14,41 & 37,21 & $-30,42$ & 21,37 & 13,29 & 39,48 & $-30,86$ & 20,21 & 12,23 & 38,86 \\
\hline & & $\begin{array}{c}\text { Control } \\
\text { (Without Mordant) }\end{array}$ & $-4,80$ & 1,04 & 3,31 & 5,92 & $-13,27$ & 8,02 & 14,88 & 1,49 & $-16,40$ & 0,28 & 17,32 & 25,97 & $-20,60$ & 13,55 & 18,36 & 30,74 \\
\hline & & Beet + Ferrous & $-34,67$ & $-0,70$ & $-13,88$ & 37,35 & $-43,70$ & 1,71 & $-9,03$ & 44,66 & $-45,75$ & 1,17 & $-10,06$ & 46,85 & $-47,72$ & 2,44 & $-10,39$ & 48,90 \\
\hline & $\frac{y}{n}$ & Beet + Alum & $-7,36$ & $-7,36$ & 2,20 & 0,95 & $-17,81$ & 10,71 & 12,12 & 24,06 & $-21,92$ & 13,56 & 13,46 & 29,07 & $-26,39$ & 16,11 & 13,17 & 33,60 \\
\hline & $=$ & Beet + Copper & $-5,10$ & $-3,59$ & $-0,26$ & 6,25 & $-13,60$ & 1,11 & 13,90 & 19,48 & $-21,04$ & 4,78 & 16,40 & 27,10 & $-23,57$ & 9,02 & 16,26 & 30,02 \\
\hline & & Beet + Vinegar & $-3,46$ & 2,06 & 2,14 & 4,55 & $-12,77$ & 8,86 & 13,27 & 20,43 & $-16,93$ & 10,60 & 15,30 & 25,15 & $-19,50$ & 13,29 & 15,65 & 28,31 \\
\hline & & Synhetic Dye & $-20,12$ & 15,46 & 9,54 & 27,11 & $-24,95$ & 17,96 & 12,25 & 33,08 & $-27,23$ & 18,52 & 11,99 & 35,04 & $-28,91$ & 18,35 & 10,41 & 35,79 \\
\hline & & $\begin{array}{c}\text { Control } \\
\text { (Without Mordant) }\end{array}$ & 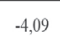 & 0,70 & 2,59 & 4,89 & $-3,17$ & 4,33 & 11,03 & 14,98 & $-10,54$ & $-10,54$ & 12,95 & 17,72 & $-13,44$ & 6,94 & 12,82 & 19,83 \\
\hline & & Beet + Ferrous & $-23,46$ & $-10,05$ & $-12,73$ & 28,52 & $-29,09$ & $-9,20$ & $-9,33$ & 31,90 & $-31,35$ & $-8,01$ & $-9,25$ & 33,65 & $-33,20$ & $-7,78$ & $-9,50$ & 35,40 \\
\hline & 常 & Beet + Alum & $-4,09$ & 0,35 & $-0,34$ & 4,11 & $-9,49$ & 5,38 & 8,49 & 13,82 & $-12,38$ & 7,48 & 11,05 & 18,20 & $-16,43$ & 8,56 & 10,56 & 21,32 \\
\hline & $\stackrel{5}{5}$ & Beet + Copper & $-7,01$ & $-1,71$ & 0,45 & 7,23 & $-13,55$ & 1,86 & 8,52 & 16,11 & $-17,81$ & 3,21 & 7,91 & 19,75 & $-19,83$ & 5,06 & 9,24 & 22,45 \\
\hline & & Beet + Vinegar & $-2,35$ & 1,12 & 3,35 & 4,24 & $-5,34$ & 3,58 & 11,15 & 12,86 & $-8,59$ & 7,40 & 15,66 & 19,33 & $\cdot 12,25$ & 8,85 & 15,00 & 21,29 \\
\hline & & Synhetic Dye & $-16,40$ & 12,66 & 8,56 & 22,41 & $-19,95$ & 13,95 & 9,03 & 25,96 & $-20,89$ & 14,2 & 9,13 & 26,85 & $-21,41$ & 13,94 & 9,84 & 27,37 \\
\hline 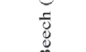 & & $\begin{array}{c}\text { Control } \\
\text { (Without Mordant) }\end{array}$ & $-4,05$ & 0,64 & 2,55 & 4,83 & $-7,09$ & 2,50 & 8,37 & 11,25 & $-8,92$ & 5,66 & 12,84 & 16,63 & $-11,74$ & 6,66 & 12,99 & 18,72 \\
\hline ज्ञ & & Beet + Ferrous & $-19,25$ & $-8,65$ & $-10,57$ & 23,60 & $-28,79$ & $-7,37$ & $-6,92$ & 30,51 & $-31,89$ & $-5,80$ & $-6,78$ & 33,11 & $-33,43$ & $-5,47$ & $-7,01$ & 34,59 \\
\hline & $\frac{9}{w}$ & Beet + Alum & $-4,61$ & $-4,61$ & 0,63 & $-0,13$ & $-9,75$ & 5,04 & 7,82 & 13,47 & $-12,22$ & 7,17 & 10,26 & 17,49 & $-16,14$ & 8,37 & 10,12 & 20,81 \\
\hline & 0 & Beet + Copper & $-3,26$ & $-1,67$ & $-0,66$ & 3,72 & $-11,56$ & 2,20 & 9,60 & 15,19 & $-15,32$ & 3,29 & 10,25 & 18,72 & $-18,52$ & 5,51 & 10,29 & 21,89 \\
\hline & & Beet + Vinegar & $-1,39$ & 1,37 & 3,25 & 3,79 & $-7,26$ & 5,04 & 12,19 & 15,05 & $-9,10$ & 6,20 & 13,21 & 17,20 & $-11,81$ & 9,23 & 15,22 & 21,36 \\
\hline & & Synhetic Dye & $-14,33$ & 11,69 & 10,68 & 21,35 & $-18,30$ & 13,33 & 10,66 & 25,02 & $-18,91$ & 13,63 & 11,12 & 25,83 & $-19,41$ & 13,78 & 10,78 & 26,13 \\
\hline
\end{tabular}



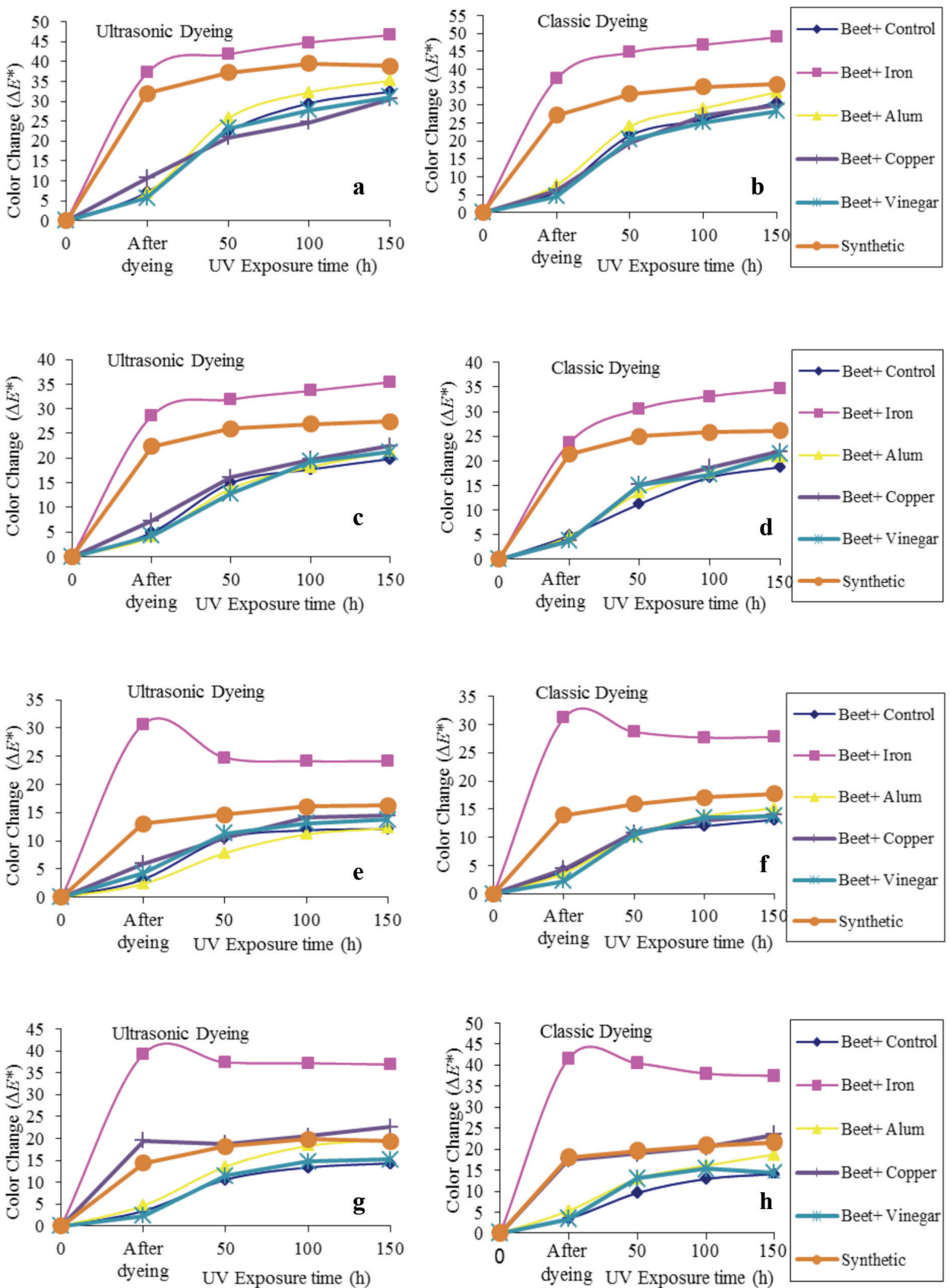

a. Scots pine/ultrasonic dyeing, b. Scots pine/Classic dyeing, c. Oriental beech/ultrasonic dyeing, d. Oriental beech/Classic dyeing, e. Walnut/ultrasonic dyeing, f. Walnut/Classic dyeing, g. Oak/ultrasonic dyeing, h. Oak/Classic dyeing.

Figure 2. Color changes of wood species exposed to $50 \mathrm{~h}, 100 \mathrm{~h}$ and $150 \mathrm{~h} \mathrm{UV}$ irradiation. 


\section{CONCLUSIONS}

Vinegar mordant applications provide resistance as much as other mordant applications; thus, a 100\% natural dyestuff for wood surfaces is developed by using natural mordant in natural dye application. Ferrous sulphate is observed to be the mordant type with the highest color change among all the wood types in general. Generally beetroot extracts and mordant mixes were showed better color change performance compared to synthetic dye. Dyeing method has not affected the color changes results.

Generally mordants in use to have color variation and to retain the stain on wood material. Wood materials colored with metal mordants mixes had darker colors, but it seems metal mordant had negative effect on color change performances. These may have explained with the reactions between wood material and mordant mixes and definitely the effect of UV irradiation on different colors. Dark colors could absorption the light maximum in ratio 98\%, and transparent colors $11 \%$. Therefore darker wood species could have been much more color changes. As a matter of fact wood species colored with beet root + mordant mixes after weathering hold much more esthetic appearances. Mordant mixture extracts that can be preferred in places of the color change may be omitted.

In conclusion of these study, natural plant sources that have a great potential, but are not benefited will be able to be activated through ensuring and disseminating usage of natural dye plant extracts harmless to environmental and human health as colorant and protective materials in surface treatments for furniture products, and by means of proliferation thereof, new line of business will emerge. Therefore, more economical and eco-friendly compared to synthetic dyes, wood paints may be developed. 


\section{ACKNOWLEDGEMENT}

This manuscript is prepared from the outcome of the project titled "Determination of leaching performance and color stability under UV-accelerated weathering conditions for wood surfaces that were treated with natural stain by ultrasonic assisted dyeing method" This project is supported by TÜBİTAK TOVAG “1001- The Support Program for Scientific and Technological Research Projects". Project number: 110 O 141.

\section{REFERENCES}

Bechtold, T.; Mussak, R. 2009. Handbook of Natural Colorants. John Wiley \& Sons, Ltd. p.432. ISBN: 978-0-470-51199-2

Cheng, M.; Brown, S.K. 2003. VOCs identified in Australian indoor air and product emission environments. Proceedings of National Clean Air Conference, 23-27 Nov. Newcastle.

Feist, W.C.; Hon, D.N.S. 1984. Chemistry of weathering and protection. In: The chemistry of solid wood, R.M. Rowell, ed. Advances in chemistry series 207, Am. Chem. Soc., Washington D.C.USA

Garcia, R.A.; Lopes, J.O.; Nascimento, A.M.; Latorraca, J.V.F. 2014. Color stability of weathered heat-treated teak wood. Maderas. Ciencia. tecnología16(4):453-462.

Goktas, O.; Duru, M.; Yeniocak, M.; Ozen, E. 2008a. Determination of the color stability of an environmentally friendly wood stain derived from laurel (Laurus nobilis L.) leaf extracts under UV exposure. Forest Prod J 58(1-2): 77-80.

Goktas, O.; Baysal, E.; Ozen, E.; Mammadov, R.; Duru, M.E. 2008b. Decay resistance and color stability of wood treated with Juglans regia extract. Wood Res 53(3): 27-36.

Goktas, O.; Ozen, E.; Baysal, E.; Mammadov, R.; Alma, M.H.; Sonmez, A. 2009a. Color stability of wood treated with madder root (Rubia tinctorium L.) extract after light fastness test. Wood Res 54(1): 37-44.

Goktas, O.; Ozen, E.; Duru, M.E.; Mammadov, R. 2009b. Determination of the color stability of an environmentally-friendly wood stain derived from oleander (Nerium oleander L.) leaf extracts under UV exposure. Wood Res 54(2): 63-72.

Goktas, O.; Ozen, E.; Duru, M.E.; Alma, M.H. 2009c. Determination of the color stability of an environmentally-friendly wood stain from saffron (Crocus sativus L.) extracts under UV exposure. Wood Res 54(4): 111-118.

Grubben, G.J.H.; Denton, O.A. 2004. Plant Resources of Tropical Africa 2. Vegetables. PROTA Foundation, Wageningen; Backhuys, Leiden; CTA, Wageningen.

Hon, D.N.S.; Feist, W.C. 1992. Hydroperoxidation in photoirradiated wood surfaces. Wood Fiber Sci 24: 448-455.

ISO 2470. 2008. Measurement of Diffuse Blue Reflectance Factor - Part 2: Outdoor Daylight Conditions (D65 Brightness). 
M.P.J.; Cardoso, L.P.; Pinto, Rodrigo, M.S.; Pereira, M.; Soares, N.F.; Miltz, J. 2011. Irradiated beetroot extract as a colorant for cream cheese. Radiation Physics and Chemistry 80(1): 114-118.

Kamdem, D.P.; Grelier, S. 2002. Surface roughness and color change of copper amine and UV absorber-treated red maple (Acer rubrum) exposed to artificial ultraviolet light. Holzforschung 56(5): 473-478.

Lin, S.Y.; Kringstad, K.P. 1970. Photosensitive groups in lignin and lignin model compounds. Tappi 53: 658-663.

Mirjalili, M.H.; Moyano, E.; Bonfill, M.; Cusido, R.M.; Palazon, J. 2011. Overexpression of the Arabidopsis thaliana squalene synthase gene in Withania coagulans hairy root cultures. Biologia plantarum 55(2): 357-360.

Mo, J.; Zhang, Y.; Xu, Q.; Lamson, J.J.; Zhao, R. 2009. Photocatalytic Purification of Volatile Organic Compounds in Indoor Air: A Literature Review. Atmospheric Environment 43(14): 2229-2246.

Ozen, E.; Yeniocak, M.; Colak, M.; Goktas, O.; Koca, I. 2014. Colorability of wood material with Punica granatum and Morus nigraextracts. BioRes 9(2): 2797-2807.

Peker, H.; Atılgan, A.; Ulusoy, H.; Goktas, O. 2012. Usage opportunities of the natural dye extracted from acorn (Quercus ithaburensis Decaisne) in the furniture industry upper surface treatment. Int J Phys Sci 7(40): 5552-5558.

Salthammer, T.; Schwarz, A.; Fuhrmann, F. 1998. Emission of reactive compounds and secondary products from wood-based furniture coatings. Atmospheric Environment 33: 75-84.

Salthammer, T.; Schwarz, A.; Fuhrmann, F. 1999. Emission of reactive compounds and secondary products from wood-based furniture coatings. Atmos Environ 33: 75-84.

Salthammer, T.; Bednarek, M.; Fuhrmann, F.; Funaki, R.; Tanabe, S.I. 2002. Formation of organic indoor air pollutants by UV-curing chemistry. J Photoch Photobio A 152 (1-3): 1-9.

Sivakumar, V.; Lakshmi, A.J.; Vijayeeswarri, J.; Swaminathan, G. 2009. Ultrasound Assisted Enhancement in Natural Dye Extraction from Beetroot for Industrial Applications and Natural Dyeing of Leather. Ultrasonics Sonochemistry 16: 782-789.

Temiz, A.; Yildiz, U.C.; Ismail, A.; Morten, E.; Gry, A.; Colakoglu, G. 2005. Surface roughness and color characteristics of wood treated with preservatives after accelerated weathering test. Appl Surf Sci 250(1-4): 35-42.

Tereza, C.M.P.; Santos, K.O.; Rubim, J.C. 2004. A spectrocolorimetric study on the effect of ultraviolet irradiation of four tropical hardwoods. Bioresource technology 93: 37-42.

TS 2470. 2005. Wood - Sampling Methods and General Requirements for Physical and Mechanical Tests. TSE, Ankara.

TS 2471. 2005. Wood, Determination of Moisture Content for Physical and Mechanical Tests. TSE, Ankara. 
Wang, L.; Weller C.L. 2006. Recent Advances In Extraction Of Nutraceuticals From Plants. Trends in Food Science \& Technology 17: 300-312.

Weschler, C.J.; Shields, H.C. 1997. Potential reactions among indoor pollutants. Atmos Environ 31: 3487-3495.

Williams, R.S. 2005. Weathering of wood. In: Rowell, R.M. (ed) Handbook of wood chemistry and wood composites. CRC Press, Florida, pp. 139-185. 